2015-06

\title{
A Robust Bearing Fault Detection and Diagnosis Technique for Brushless DC Motors Under Non-stationary Operating Conditions
}

\author{
Abed, W
}

http://hdl.handle.net/10026.1/3638

10.1007/s40313-015-0173-7

Journal of Control, Automation and Electrical Systems

Springer Science and Business Media LLC

All content in PEARL is protected by copyright law. Author manuscripts are made available in accordance with publisher policies. Please cite only the published version using the details provided on the item record or document. In the absence of an open licence (e.g. Creative Commons), permissions for further reuse of content should be sought from the publisher or author. 
A Robust Bearing Fault Detection and Diagnosis Technique for Brushless DC Motors Under Non-stationary Operating Conditions

\section{Wathiq Abed, Sanjay Sharma, Robert Sutton \& Amit Motwani}

Journal of Control, Automation and Electrical Systems

formerly CONTROLE \& AUTOMAÇÃO

ISSN 2195-3880

J Control Autom Electr Syst

DOI 10.1007/s40313-015-0173-7
Journal of

ONLINE

FIRST

Control, Automenun 8 Electrical Systems

Formerly Controle \& Automação

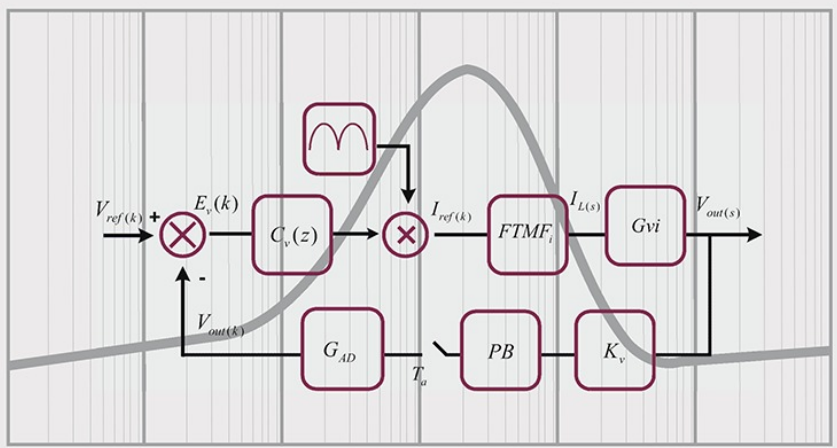

(7) Springer

26(2) $105-190$ (2015)

şa

\section{自 Springer}


Your article is protected by copyright and all rights are held exclusively by Brazilian Society for Automatics--SBA. This e-offprint is for personal use only and shall not be selfarchived in electronic repositories. If you wish to self-archive your article, please use the accepted manuscript version for posting on your own website. You may further deposit the accepted manuscript version in any repository, provided it is only made publicly available 12 months after official publication or later and provided acknowledgement is given to the original source of publication and a link is inserted to the published article on Springer's website. The link must be accompanied by the following text: "The final publication is available at link.springer.com". 


\title{
A Robust Bearing Fault Detection and Diagnosis Technique for Brushless DC Motors Under Non-stationary Operating Conditions
}

\author{
Wathiq Abed · Sanjay Sharma • Robert Sutton • \\ Amit Motwani
}

Received: 12 May 2014 / Revised: 19 January 2015 / Accepted: 25 February 2015

(C) Brazilian Society for Automatics-SBA 2015

\begin{abstract}
Rolling element bearing defects are among the main reasons for the breakdown of electrical machines, and therefore, early diagnosis of these is necessary to avoid more catastrophic failure consequences. This paper presents a novel approach for identifying rolling element bearing defects in brushless DC motors under non-stationary operating conditions. Stator current and lateral vibration measurements are selected as fault indicators to extract meaningful features, using a discrete wavelet transform. These features are further reduced via the application of orthogonal fuzzy neighbourhood discriminative analysis. A recurrent neural network is then used to detect and classify the presence of bearing faults. The proposed system is implemented and tested in simulation on data collected from an experimental setup, to verify its effectiveness and reliability in accurately detecting and classifying the various faults.
\end{abstract}

Keywords Fault diagnosis - Rolling bearing - Feature extraction $\cdot$ Feature reduction $\cdot$ Recurrent neural network

\section{Introduction}

Condition monitoring and fault diagnosis of electric motors is necessary to optimise maintenance and improve reliability levels in critical applications such as in aircraft ailerons and rudders (Brown et al. 2009). Faults typically start off as marginal defects which escalate over time.

W. Abed $(\varangle) \cdot$ S. Sharma $\cdot$ R. Sutton $\cdot$ A. Motwani

School of Marine Science and Engineering, University of Plymouth, Plymouth, UK

e-mail: Wathiq.abed@plymouth.ac.uk
Early fault detection and diagnosis (FDD) with condition monitoring renders it possible to perform important prevention actions, thereby avoiding economically damaging losses of elements and parts, through an adequate maintenance management system, as well as avoiding stalled production (Tavner 2008).

Bearing faults are common faults in electric motors and represent about 40-50\% of all motor faults (Jin et al. 2013).

The bearings of motors used in industrial applications are typically subject to non-ideal conditions such as overloading, misalignment, electrical fluting and inadequate lubrication (Wu et al. 2013). A bearing structure consists of an inner and outer race, or ring with grooves, and a set of balls or rolling elements placed between these, as shown in Fig. 1. where $\mathrm{B} d$ : The ball diameter, $\mathrm{p} d$ : The diameter of the bearing it measured from ball centre to opposite ball centre and $\beta$ : The contact angle.

Bearing faults can be classified into two main categories: a single localised defect on a bearing surface, and a generalised roughness where a large area of the bearing surface has degraded and become irregular (Zhenyu et al. 2009).

The result of such defects is the continued loss of the geometric accuracy of the rolling contact surfaces, and gradual deterioration of the bearing function, leading to increased deflection, friction, temperature and vibration.

Many techniques have been used for rolling element bearing fault diagnosis and can be classified depending on the type of measurement involved. These can be, for example, vibration, temperature (Patil et al. 2010) or acoustic measurements (Delgado et al. 2011).

Vibration measurement is the most widely used and effective way to detect rolling bearing faults, but does not give a clear indication of faults at low speed. Vibration can be picked up from other mechanical parts, thus leading to false positives. Furthermore, because vibration signals are related to all 


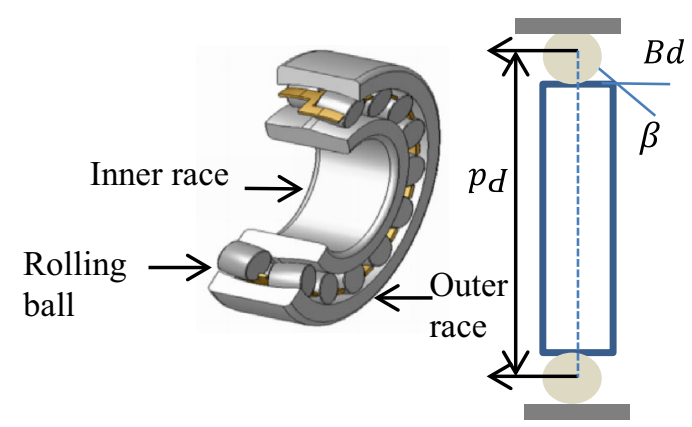

Fig. 1 Main bearing design parameters

the mechanical elements, they only allow for fault detection rather than fault diagnosis. In order to increase fault diagnosis reliability, especially for critical applications, in addition to vibration, the stator current signal can be used as another fault indicator (Trajin et al. 2009).

It has been shown to be an effective rolling element bearing fault indicator, especially at low motor speeds (Immovilli et al. 2010). Moreover, the use of a current sensor does not necessarily increase the cost of the system, as current sensors already form part of power protection circuits used in such systems (Bediaga et al. 2013).

Thus, the combined use of both vibration and current signals will provide a more robust fault detection and diagnosis system without a significant increase in cost, and this is the approach used in this work.

From the measured vibration and current signals, the discrete wavelet transform (DWT) is used to obtain the best features from the signals. Wavelet transformations have been shown to be a powerful tool for dealing with non-stationary vibration signals. Kankar et al. (2011) presented two criteria to select the best wavelet features: the first of these is based on using maximum energy-to-Shannon entropy ratio, while the second is based on maximum relative wavelet energy.

To reduce additional computational time for fault classification, an accurate dimensionality reduction tool is needed to select the most informative features from the wavelet feature set. Different feature reduction methods such as principle component analysis (PCA) (Zhang et al. 2013) and empirical mode decomposition (EMD) (Camarena et al. 2014) have been used to reduce feature redundancy.

In this work, orthogonal fuzzy neighbourhood discriminant analysis (OFNDA), mostly used in medical data analysis but not previously used in electrical motor fault diagnosis systems, is implemented as a new approach for feature reduction. Basically, OFNDA works to maximise the distance between features belonging to different classes, while minimising the distance between features in the same class (Khushaba et al. 2010).

Recently, artificial intelligence (AI) has been introduced into the fault diagnosis process for condition monitoring, including techniques based on fuzzy logic (FL) (Xu et al. 2009), neural networks (NN) (Mahammed and Hiyama 2011), genetic algorithms (GA) (Samanta et al. 2004), adaptive neuro fuzzy inference systems (ANFIS) (Yilmaz and Ayaz 2009) and support vector machines (SVM) (Sugumaran and Ramachandran 2011). AI aims to generate classifying expressions simple enough to be understood easily by humans (Michie et al. 2009).

Diagnostics of electrical motors operating under constant speed conditions have been extensively investigated in the literature (Yang et al. 2002; Subhasis et al. 2005) and (Rao et al. 2012). For example, artificial neural networks (ANN) provide an excellent mathematical tool for modelling nonlinear systems, and static multilayer perceptron (MLP) type ANNs trained using the Back- Propagation (BP) algorithm have been extensively applied for the fault detection task under stationary operating conditions (Vachtsevanos and Wang 2001).

However, the response of a static network at any instant in time depends only on the value of the input sequence at that same time instant. In real-life applications, there are several circumstances where the motor is never operating at a constant speed or with a constant load, such as in automotive and aircraft applications (Sadough Vanini et al. 2014).

Dynamic neural networks (DNN) are more versatile than their static counterparts and provide the capability to learn the dynamics of complicated nonlinear systems that conventional static neural networks cannot model (Xuhong and Yigang 2005). DNNs have been successfully applied for fault diagnosis (Hyun et al. 2010), and studies have shown that their use can improve the fault prediction accuracy of electric motor condition monitoring systems.

The aim of the work presented here is to develop a new bearing FDD scheme for Brushless DC (BLDC) motors for use in high performance applications, which can accurately detect faults in real time and provide useful information about the same. In order to achieve this, the novel use of OFNDA features containing meaningful information is fed to a DNN, to diagnose faults during motor operation.

Another novelty lies in the experimental tests carried out using the aforementioned technique to recognise and classify three different types of localised bearing faults: cracks in both inner and outer races, and crushed bearing-balls. Furthermore, while previous work has dealt with fault diagnosis under stationary operating conditions, in the present work the rolling element bearing faults are diagnosed under nonstationary load and motor speed conditions.

The technique developed here has also been used successfully to diagnose unbalanced mechanical loads in trolling or permanent magnet brushed DC motors (Abed et al. 2014) as well as its used to diagnosis bearing fault sunder stationary operating conditions (Abed et al. 2014).

With regard to the structure and content of the paper, following on from this introductory material, Sect. 2 describes 


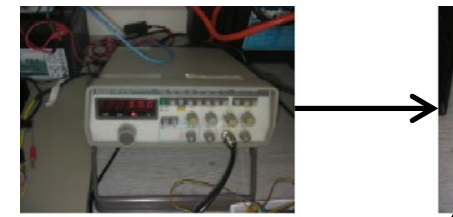

Function generator

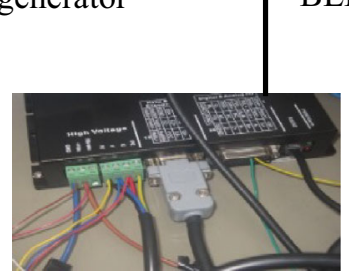

DSD806 Digital Drive

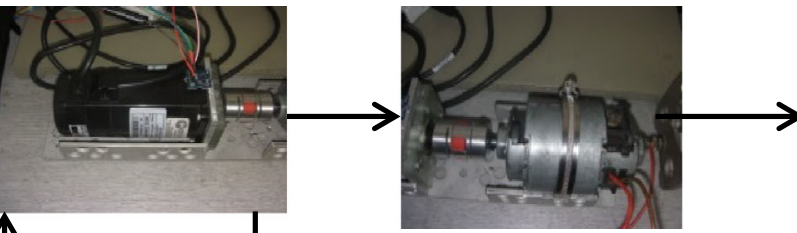

Experiential DC motor with flexible coupling

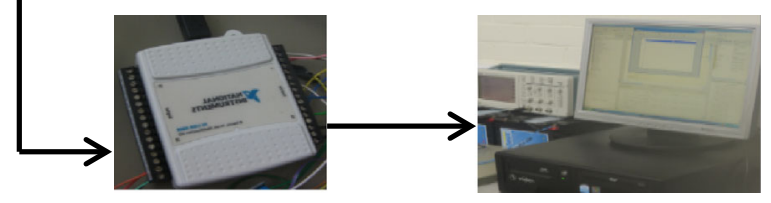

Data acquisition system
Fig. 2 Experimental arrangement

the experimental setup and data acquisition system. Section 3 outlines the fault diagnosis process used in this study, while Sect. 4 details the feature extraction and dimensionality reduction techniques employed. Section 5 describes the innovative fault classification procedure based on a RNN. Section 6 presents the experimental results obtained and lastly, conclusions are drawn in Sect. 7.

\section{Experimental Setup and Data Acquisition}

A laboratory prototype motor driver has been built for the experimental setup, as shown schematically in Fig. 2. Table 1 lists the components used for this setup. It consist of a $1.2 \mathrm{~kW}, 4000 \mathrm{rpm}, 50 \mathrm{~Hz}$ three phase BLDC motor, connected through a flexible coupling (D30 L42 SY) to a permanent magnet DC motor operating as a generator and acting as a load. The load was varied by using a rheostat connected to the permanent magnet motor. A $24 \mathrm{~V}$ lead-acid battery was used to supply the BLDC motor, through a digital servo drive DSD806. A three-axis accelerometer ADXL325 with a full-scale range of $\pm 5 \mathrm{~g}$ and bandwidth of $0.5-1600 \mathrm{~Hz}$ was mounted on the motor bearing to collect vibration signals. Additionally, a current sensor ACS714 was used to read the stator current.

Data from both the sensors were logged to a PC using a data acquisition system (NI USB-6009) multifunction I/O device at a sampling rate of $3 \mathrm{kHz}$ for 30 s periods. WM1 Ball Bearings (6000 ZZ) have been used for the study with the following characteristics: a ball diameter $(\mathrm{B} d)$ of $3 \mathrm{~mm}$, a bearing diameter $(\mathrm{P} d)$ of $25 \mathrm{~mm}$, inner diameter of $14 \mathrm{~mm}$.

Data were logged under healthy operating conditions as well as with the motor running with each type of bearing defect (Jin et al. 2013) (inner, outer and ball faults) as shown in Fig. 3. For each of these, the tests were carried out at three different constant speeds (600, 900 and $1200 \mathrm{rpm})$, while
Table 1 Experiment setup requirements

\begin{tabular}{ll}
\hline Item & Equipment \\
\hline 1 & BLDC motor \\
2 & Flexible coupling \\
3 & DC generator \\
4 & Motor driver \\
5 & DC power supply \\
6 & Variable resistive load \\
7 & Data acquisition system \\
\hline
\end{tabular}

varying the load from no-load to $100 \%$ of the rated load, and then again at three different constant loads (no load, 50\% rated load and $100 \%$ rated load) while varying the speed from 600 to $1200 \mathrm{rpm}$. Thus, 24 distinct tests were carried out to record data under normal and abnormal non-stationary operating conditions.

\section{Fault Diagnosis Process}

The proposed methodology as illustrated in Fig. 4 contains three stages: first stage is data collection during experiment test (stator current and vibration signals); second stage is features extraction and reduction and the last stage is fault classification using a DNN.

It can be seen from the vibration and current signals that the amplitude of the time waveform signal under a fault defect is much more than in fault free cases, and generally, the amplitude of the time waveform signal decreases when the load decreases.

Figures 5, 6, 7 and 8 plot the current and vibration signals, and their respective frequency characteristics, of a BLDC motor operating under normal conditions and with different bearing faults, at full load and variable speeds. The signals were sampled at $3 \mathrm{KHz}$ and have a duration of $30 \mathrm{~s}$. 


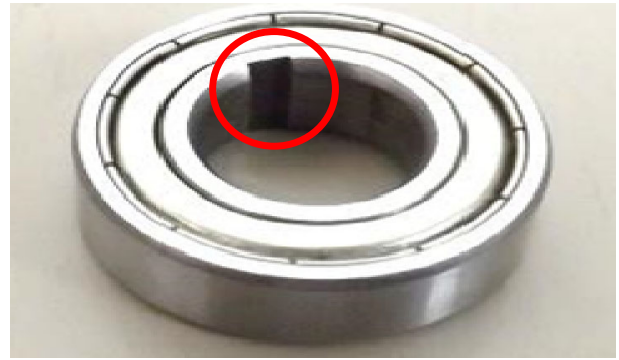

(a)

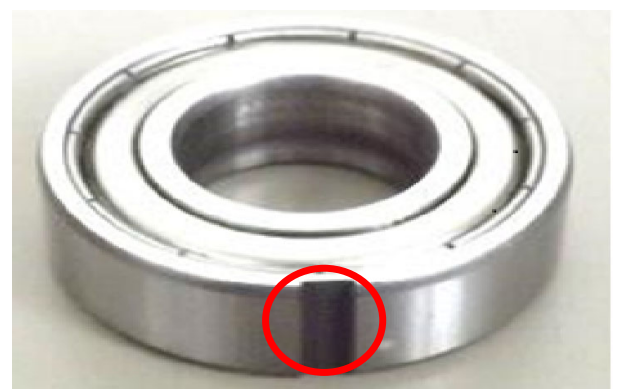

(b)

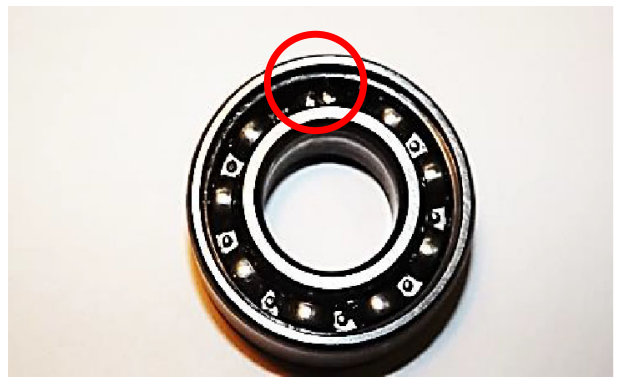

(c)

Fig. 3 Bearing defects: a inner-race crack, b outer-race crack, c ball-crush defects

Figure 5 shows the original stator current and raw vibration time waveforms under normal conditions at while Figs. 6, 7 and 8 represent motor performance at bearing faults inner race, outer race and ball bearing defects respectively. Generally, the time waveform is very complicated and the general vibration level of the signal is higher than under normal conditions. As can be seen from the vibration and current signals, the amplitude of the time waveform under fault defects is much more than in the fault free case, and generally, the amplitude of the time waveform decreases when load decreases.

\section{Feature Extraction and Dimension Reduction}

When a single localised bearing fault occurs, the contact between the local defect and its mating surface produces an impulse with a short duration and an approximately exponential damping rate. If the rotational speed is constant, the impulse will repeat at a constant interval and this repeti-

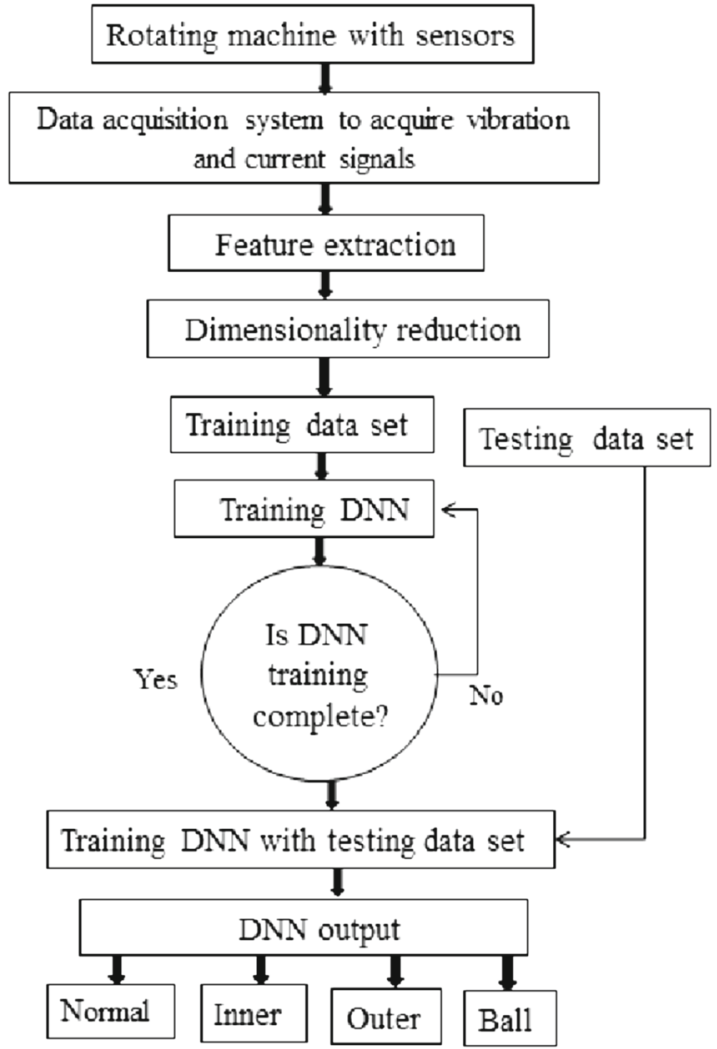

Fig. 4 Fault diagnosis process

tion frequency of impulses is called the fault characteristic frequency (Wang et al. 2014). However, bearings often work under non-stationary conditions (variable speed, variable load).

In such operating conditions, the impulses do not appear periodically and hence the envelope analysis methods, as well as any other techniques based on the assumption of constant rotating speed, are no longer applicable. Feature extraction is usually the first step in any pattern recognition system following the pre-processing step.

Extracting the most significant features is crucially important in most pattern recognition problems.

Motor signals may be processed using three techniques: time-domain analysis, frequency-domain analysis, and timefrequency analysis. Frequency analysis using fast Fourier transform (FFT) is not suitable for non-stationary signals. On the other hand, Short Time Fourier Transform (STFT) has limitations related to constant windows for all frequencies and is computationally expensive.

Wavelet transforms (WT), on the other hand, have the ability to explore signal features with partial characteristics and analyse signals with different time and frequency resolutions (Goharrizi and Sepehri 2010). Mathematically, the wavelet and scaling functions can be represented as the following expressions (Seshadrinath et al. 2014): 


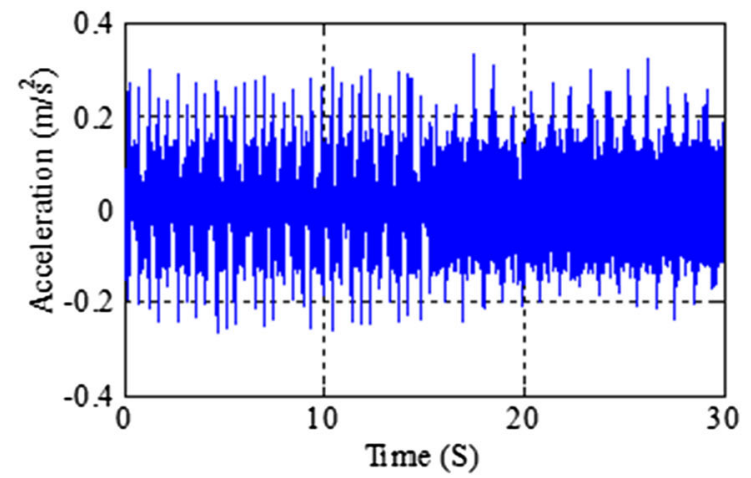

(a) vibration signal

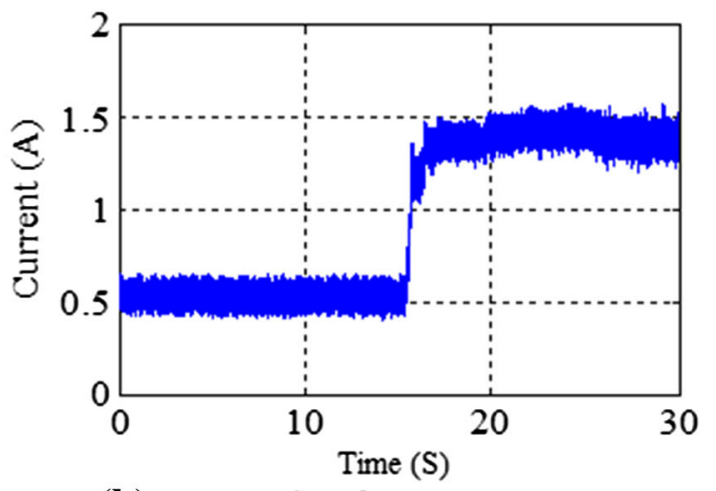

(b) current signal

Fig. 5 Vibration and current signals for motor operating at variable speed and full load with healthy bearing

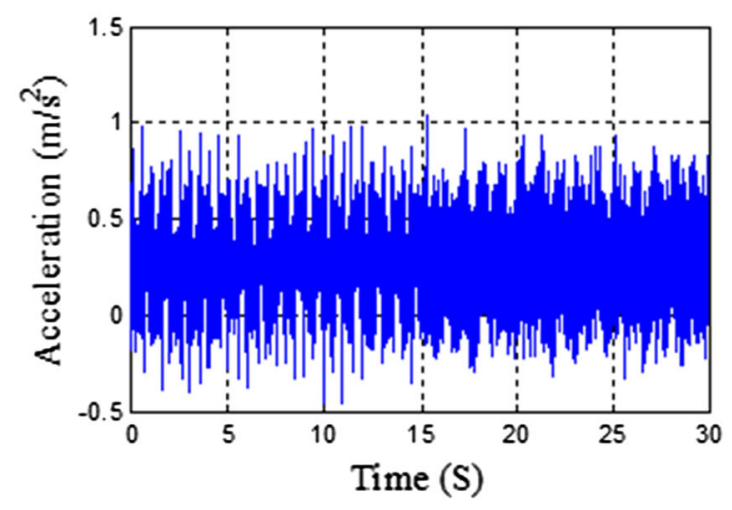

(a) vibration signal

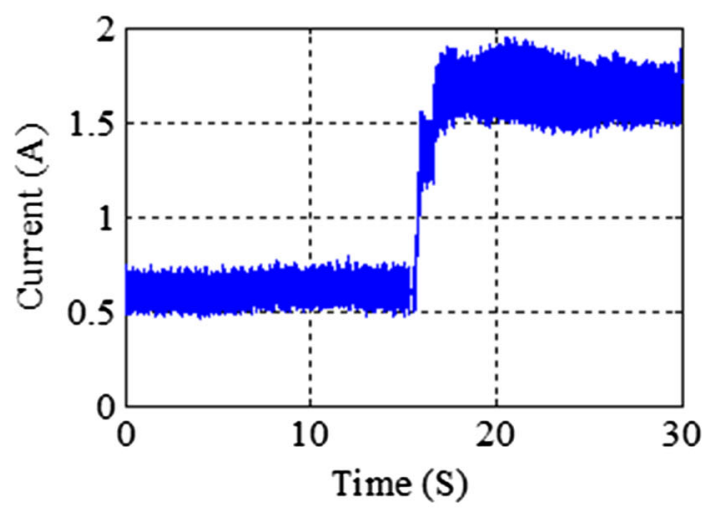

(b) current signal

Fig. 6 Vibration and current signals for motor operating at variable speed and full load with inner-race crack bearing fault

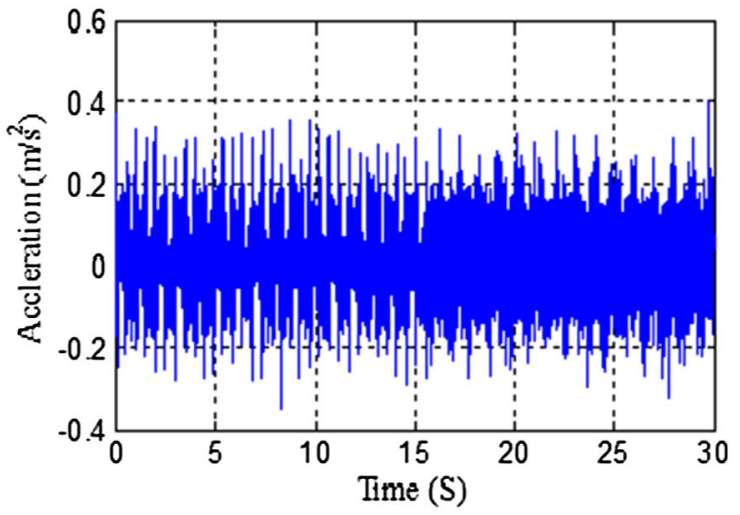

(a) vibration signal

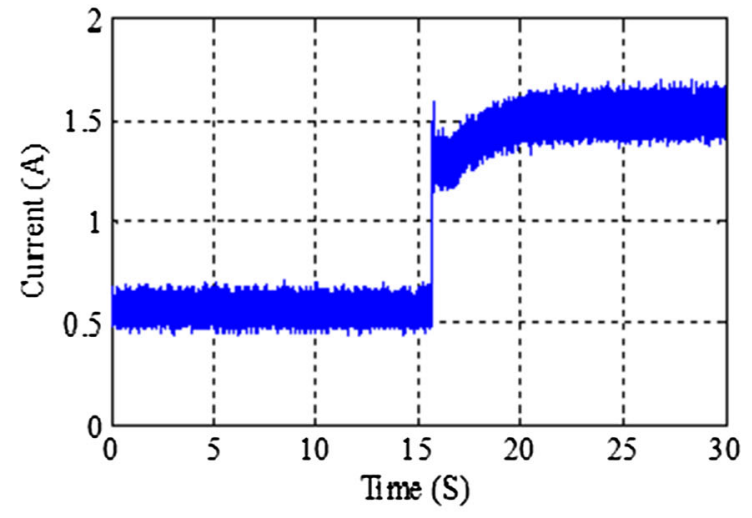

(b) current signal

Fig. 7 Vibration and current signals, and respective frequency spectra, for motor operating at variable speed and full load with outer-race crack bearing fault

$$
\begin{aligned}
x(t)= & \sum_{n=-\infty}^{\infty} c(n) \emptyset(t-n \\
& +\sum_{n=0}^{\infty} \sum_{n=\infty}^{\infty} d(j, n) 2^{j / \pi} \gamma\left(2^{j} t-n\right)
\end{aligned}
$$

The scaling $c(n)$ and wavelet $d(j, n)$ coefficients for level $j$ are computed as

$$
c(n) \int_{-\infty}^{\infty} x(t) \emptyset(t-n) d t
$$



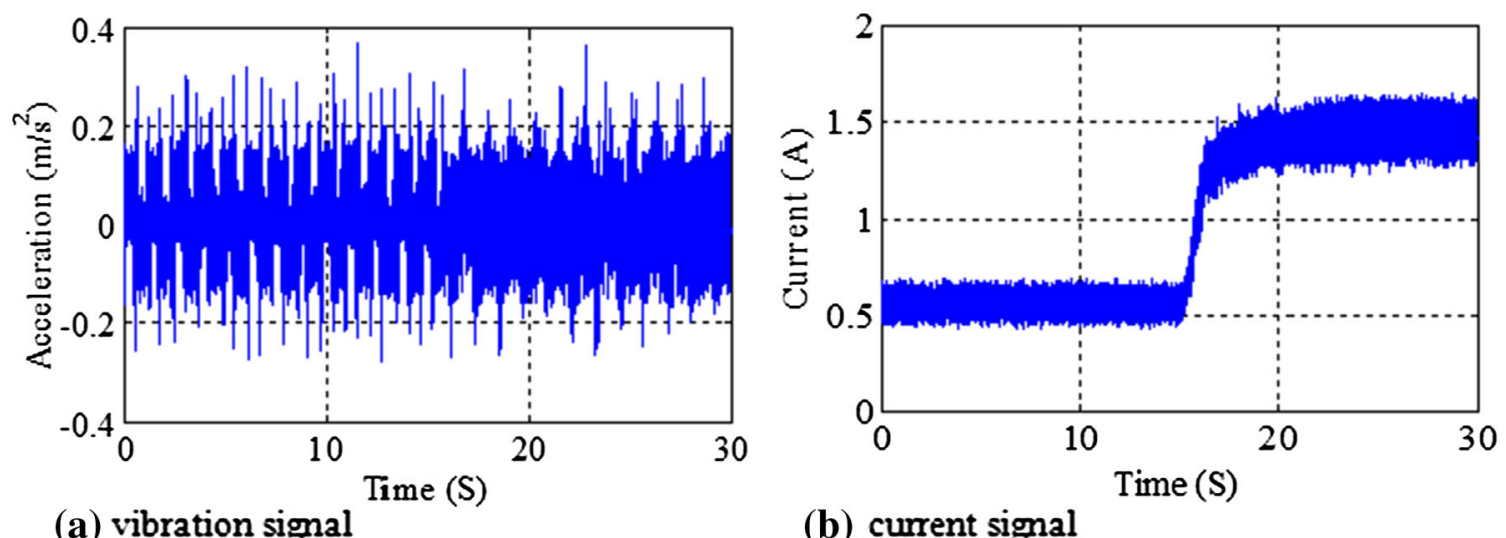

(b) current signal

Fig. 8 Vibration and current signals, and respective frequency spectra, for motor operating at variable speed and full load with crushed ball bearing fault

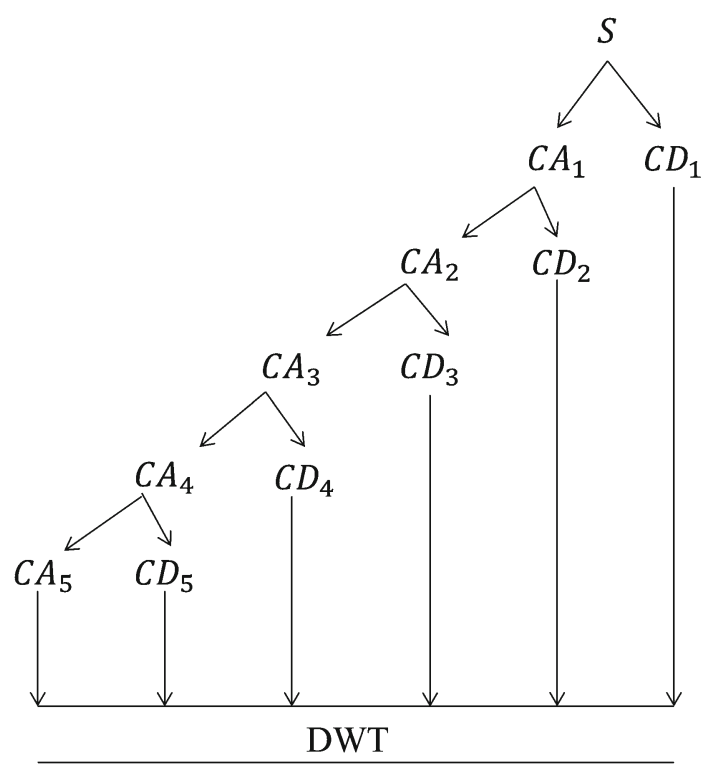

Fig. 9 Discrete wavelet decomposition

$$
d(j, n)=2^{j / 2} \int_{-\infty}^{\infty} x(t) \emptyset(t-n) d t
$$

The DWT approach has been successfully applied to detect and locate faults, together with identification of the severity of the faults (Seshadrinath et al. 2012). The same approach can be extended to identify other types of faults, with a significant reduction in the computation time compared to other signal processing techniques (Jun et al. 2013). The three levels of discrete wavelet decomposition are shown in Fig. 9. At each level, the original signal $\left(A_{o}(k)\right)$ is decomposed using low $g[n]$ and high pass filters $h[n]$ into a detail $\left(d_{j}\right)$ component, which represents the high frequency components and approximations $\left(a_{n}\right)$, which are the low frequency components, by correlating the scaled and shifted versions of the wavelet as in Eq. 4.
The correlation between the signal and the wavelet at each level of scaling and shifting is termed the wavelet coefficient. The resolution of the signal, which is a measure of the amount of detail of information in the signal, is changed by the filtering operations, and the scale is changed by changing the window size. Resulting from the DWT decomposition, a set of wavelet energy signals $\left(d_{j}\right)$ and $\left(a_{j}\right)$ are obtained and can be described as (Antonino et al. 2013):

$$
\begin{aligned}
A_{o}(k) & =\sum \vartheta_{i}^{m} \cdot \theta_{i}^{m}(t)+\sum_{j=1}^{m} \sum_{i} \alpha_{i}^{j} \cdot \phi_{i}^{j} \\
& =a_{n}(t)+d_{n}(t)+\cdots+d_{1}
\end{aligned}
$$

The choice of mother wavelet in DWT is important for better resolution of the signal in time and frequency domains and selected by trial and error. Deubechies (db2, db4, sym4 and coif2) were tested and according to Safavian et al. (2005), $\mathrm{db} 4$ was found to be suitable in detecting transient behaviour in power system signals.

In the present work, six features were obtained for each signal: five details (d1, d2, d3, d4, d5) and one approximation (a1) using db4 as the mother wavelet function. It can be observed from Tables 2 and 3 that the wavelet energy of the detail coefficients $\mathrm{d} 1$ are varied after the occurrence of a fault under both variable load and variable speed conditions, by 50 and $76 \%$, respectively.

The two signals (current and vibration) thus provided a total of twelve features. Each combined time-signal $(900,000$ samples for both current and vibration) was divided into 3600 windows of 250 data-points. The information extracted by DWT was then forwarded to the feature reduction stage. Table 4 shows the number of decomposition levels and their frequency bands selected for this study. DWT is successful in analysing non-stationary signals.

However, DWT yields a high-dimensional feature vector (Phinyomark et al. 2012) and in some cases the number of features is relatively larger than the number of training samples, usually referred to as the curse of dimensional- 
Table 2 Wavelet energy (details and approximate) under variable load condition/Joule

\begin{tabular}{|c|c|c|c|c|c|}
\hline a5 & $\mathrm{d} 1$ & $\mathrm{~d} 2$ & d3 & $\mathrm{d} 4$ & d5 \\
\hline 99.942 & 0.028 & 0.010 & 0.006 & 0.007 & 0.008 \\
\hline \multicolumn{6}{|c|}{ Healthy } \\
\hline 99.074 & 0.534 & 0.170 & 0.119 & 0.063 & 0.056 \\
\hline \multicolumn{6}{|c|}{ Faulty bearing at $1200 \mathrm{rpm}$ and variable load } \\
\hline 99.773 & 0.128 & 0.026 & 0.020 & 0.016 & 0.033 \\
\hline \multicolumn{6}{|c|}{ Faulty bearing $900 \mathrm{rpm}$ and variable load } \\
\hline 99.913 & 0.056 & 0.015 & 0.007 & 0.003 & 0.012 \\
\hline \multicolumn{6}{|c|}{ Faulty bearing $600 \mathrm{rpm}$ and variable load } \\
\hline
\end{tabular}

Table 3 Wavelet energy (details and approximate) under variable speed/Joule

\begin{tabular}{|c|c|c|c|c|c|}
\hline a5 & d1 & $\mathrm{d} 2$ & d3 & $\mathrm{d} 4$ & d5 \\
\hline 99.885 & 0.067 & 0.016 & 0.010 & 0.010 & 0.010 \\
\hline \multicolumn{6}{|c|}{ Faulty bearing variable speed and full load } \\
\hline 99.722 & 0.144 & 0.048 & 0.030 & 0.026 & 0.031 \\
\hline \multicolumn{6}{|c|}{ Faulty bearing variable speed and half rated load } \\
\hline 99.722 & 0.143 & 0.047 & 0.030 & 0.026 & 0.030 \\
\hline \multicolumn{6}{|c|}{ Faulty bearing variable speed no load } \\
\hline
\end{tabular}

Table 4 Wavelet frequency bands

\begin{tabular}{ll}
\hline Decomposition level & Frequency components $(\mathrm{Hz})$ \\
\hline$d_{1}$ & $3000-1500$ \\
$d_{2}$ & $1500-750$ \\
$d_{3}$ & $750-325$ \\
$d_{4}$ & $325-162.5$ \\
$d_{5}$ & $162.5-81.25$ \\
$a_{5}$ & $0-162.25$ \\
\hline
\end{tabular}

ity, adversely affecting the training and testing speed (Alok et al. 2006). An accurate dimensionality reduction tool is thus needed to remove redundant features information (Prieto et al. 2013).

Commonly, dimensionality reduction methods can be implemented as methods of feature projection and feature selection. In this paper, only the projection method is considered.

The feature projection method attempts to determine the best combination of original wavelet coefficients and additionally, the features reduced are different from the original features. OFNDA, is a better technique. Al-Timemy et al. (2013) compared it to other feature reduction techniques, such as Linear Discriminant Analysis (LDA) where singularity problems are predominant.

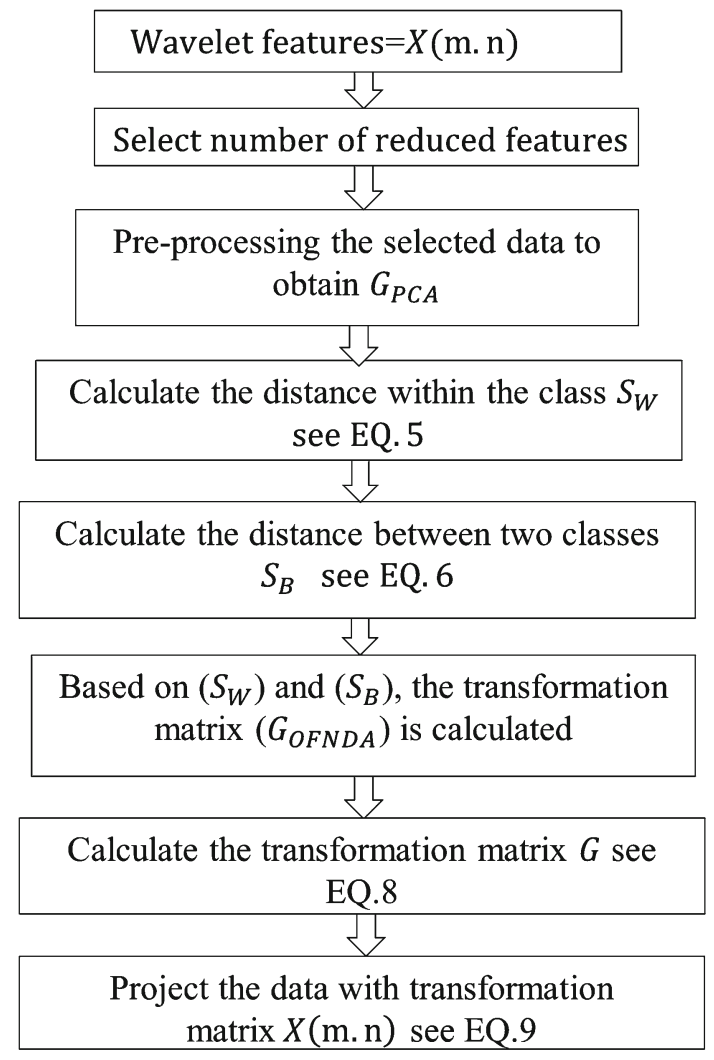

Fig. 10 The steps of OFNDA process

Orthogonal fuzzy neighbourhood discriminant analysis has been recently proposed and widely used in the analysis of medical data. Khushaba et al. (2010) present OFNDA for feature reduction, as it works to maximise the distance between features belong to different classes $\left(S_{\mathrm{b}}\right)$ while minimising the distance between features in the same class $\left(S_{\mathrm{w}}\right)$ while taking into account the contribution of the samples to the different classes. OFNDA has been successfully applied here to classify four classes of rolling element bearing defects under variable speed and load conditions.

The diagram in Fig. 10 illustrates the OFNDA process. The first step is to apply PCA to remove any redundancy that may cause singularity, before starting discriminant analysis and keeping all principle components, to prevent the loss of any useful information.

Then, the computation of the proposed fuzzy neighbourhood discriminant analysis (FNDA) proceeds by calculating the $S_{\mathrm{w}}$ and $S_{\mathrm{b}}$ as given by:

$$
\begin{aligned}
S_{\mathrm{w}} & =\sum_{\mathrm{i}=1}^{\mathrm{c}} \sum_{\mathrm{k}=1}^{1_{\mathrm{i}}} \mu_{\mathrm{ik}}\left(X_{\mathrm{k}}-X_{\mathrm{j}}\right)\left(X_{\mathrm{k}}-X_{\mathrm{j}}\right)^{\mathrm{T}} \\
S_{\mathrm{b}} & =\sum_{\mathrm{i}=1}^{\mathrm{c}} \mu_{i k}\left(U_{\mathrm{i}}-X_{\mathrm{x}}\right)\left(U_{\mathrm{i}}-X_{\mathrm{x}}\right)^{\mathrm{T}} \\
G & =G_{\mathrm{FNDA}} \cdot G_{\mathrm{PCA}}
\end{aligned}
$$


$G_{\mathrm{FNDA}} \cdot G_{\mathrm{PCA}}$ is the OFNDA transformation matrix related to PCA and FNDA, respectively.

$X(m . n)=X(m . n) \cdot G_{\mathrm{FNDA}}$

where $\mu_{i k}$ the membership of pattern k in class is $i, X_{k}$ is the $K_{\text {th }}$ sample, and $U_{i}$ is the mean of the patterns that belong to class $i$

\section{Recurrent Neural Network (RNN) for Real-time Condition Monitoring}

A DNN structure contains feedback, which, though more difficult to train, provides greater versatility than a static neural network, which contains only a feed-forward structure.

Dynamic networks have memory and can be trained to learn sequential or time-varying patterns (Howard et al. 2006).

In this work, a nonlinear auto-regressive with exogenous inputs (NARX) model was trained to detect and classify bearing faults during non-stationary operation.

This model is a type of RNN that has a delay line on the input, and the output is fed back to the input by another delay line (Yusuf et al. 2013). Such a network with one hidden layer and four output units is shown in Fig. 11.

The input consists of the three OFNDA features, $x_{1}^{\text {OFNDA }}$,

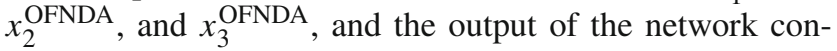
sists of four units used to indicate a particular bearing fault condition. The input pattern to the network (input layer) at each time $k$ consists of the three input features (present and delayed values), as well as the output feedback, and is formed as:

$$
\mathbf{x}(k)=\left[\begin{array}{c}
x_{1}^{\mathrm{OFNDA}}(k) \\
\vdots \\
x_{1}^{\mathrm{OFNDA}}\left(k-n_{d i_{1}}\right) \\
\vdots \\
x_{3}^{\mathrm{OFNDA}}(k) \\
\vdots \\
x_{3}^{\mathrm{OFNDA}}\left(k-n_{d i_{3}}\right) \\
\hat{y}_{1}(k-1) \\
\vdots \\
\hat{y}_{1}\left(k-n_{d o_{1}}\right) \\
\vdots \\
\hat{y}_{4}(k-1) \\
\vdots \\
\hat{y}_{4}\left(k-n_{d o_{4}}\right)
\end{array}\right]
$$

where $n_{d i_{j}}$ and $n_{d o_{j}}$ are the number of delays of input feature $j$ and output $j$ respectively. In this case, four input delays and three output delays were used for all input and output features respectively. The network used is a logistic classifier that incorporates sigmoid activations in all the hidden and output units. For each input pattern $\mathbf{x}(k)$, the output of each node is calculated by forward propagation according to

$\mathbf{a}^{(1)}(k)=\left[\begin{array}{c}1 \\ \mathbf{x}(k)\end{array}\right]$;

$\mathbf{a}^{(2)}(k)=\left[\begin{array}{l}1 \\ s\left(\boldsymbol{\Theta}^{(1)} \mathbf{a}^{(1)}(k)\right)\end{array}\right] ;$

$\hat{\boldsymbol{y}}(k)=\mathbf{a}^{(3)}(k)=s\left(\boldsymbol{\Theta}^{(2)} \mathbf{a}^{(2)}(k)\right)$

where $\mathbf{a}_{i}^{(l)}$ denotes the activation or output of the $i^{\text {th }}$ node of layer $l, \hat{\mathbf{y}}$ is the output vector of the network, $\boldsymbol{\Theta}^{(1)}$ and $\boldsymbol{\Theta}^{(2)}$

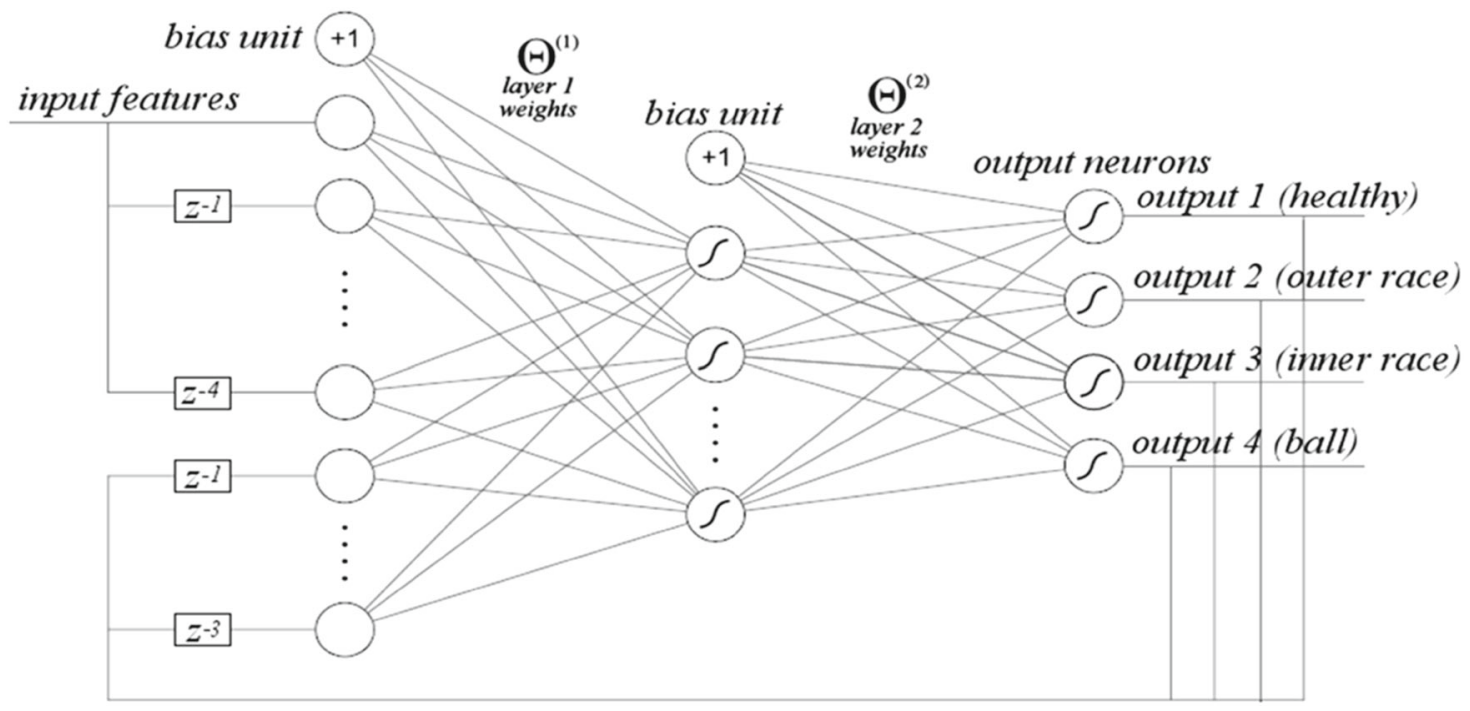

Fig. 11 RNN used for fault diagnosis 
Table 5 RNN output signification

\begin{tabular}{lllll}
\hline Output 1 & Output 2 & Output 3 & Output 4 & Indication \\
\hline 1 & 0 & 0 & 0 & Healthy \\
0 & 1 & 0 & 0 & Inner race \\
0 & 0 & 1 & 0 & Outer race \\
0 & 0 & 0 & 1 & Crushed ball \\
\hline
\end{tabular}

are the matrices of parameters of the network such that $\boldsymbol{\Theta}_{i j}^{(l)}$ represents the strength of the connection between the $j^{\text {th }}$ of layer $l$ and node $i^{\text {th }}$ node of layer $(l+1)$, and $s(x)$ is the logistic function.

$S(x)=\frac{1}{1+e^{-x}}$

For each input pattern, the network outputs four values between 0 and 1 ; these output values are rounded to 0 or 1 to indicate a certain fault condition, as shown in Table 5 .

$$
\left(\hat{\mathbf{y}}(k)=\left[\hat{\mathbf{y}}_{1}(k), \hat{\mathbf{y}}_{2}(k), \hat{\mathbf{y}}_{3}(k), \hat{\mathbf{y}}_{4}(k)\right]^{T}\right)
$$

In order to train the network, $60 \%$ of the data from each of the data-sets shown in Figs. 5, 6, 7 and 8 was used to produce input and target patterns for healthy operation and different bearing fault conditions under variable speed or variable load operating modes.

Training consists of minimising the cost function:

$$
\begin{aligned}
J= & \frac{1}{m} \sum_{k=1}^{m} \sum_{n=1}^{4}-\left[\left(\mathbf{y}_{t}\right)_{n}(k) \ln \left(\hat{\mathbf{y}}_{n}(k)\right)\right. \\
& \left.+\left(1-\left(\mathbf{y}_{t}\right)_{n}(k)\right) \ln \left(1-\hat{\mathbf{y}}_{n}(k)\right)\right]
\end{aligned}
$$

with respect to the network parameters $\boldsymbol{\Theta}^{(1)}$ and $\boldsymbol{\Theta}^{(2)}$, where $m$ is the number of training samples, and $\mathbf{y}_{t}$ is equivalent to' the target output for each one. This process was carried out recursively using the gradient descent (GD) method according to:

$\boldsymbol{\Theta}_{i j}^{(l)}:=\boldsymbol{\Theta}_{i j}^{(l)}-\alpha \Delta_{i j}^{(l)}$ for all $\boldsymbol{\Theta}_{i j}^{(l)}$

where $\Delta_{i j}^{(l)}=\frac{\partial J}{\partial \Theta_{i j}^{(l)}}$ and $\alpha$ is the learning rate, in which the initial network parameters were chosen randomly. In order to calculate the gradient components $\Delta_{i j}^{(l)}$, the BP method was used.

BP method:

For each training pattern $\mathbf{x}(k)$,

1. Obtain $\mathbf{a}^{(1)}(k), \mathbf{a}^{(2)}(k)$, and $\hat{\mathbf{y}}(k)=\mathbf{a}^{(3)}(k)$ according to (6-8)

2. $\boldsymbol{\delta}^{(3)}(k)=\mathbf{y}_{t}(k)-\hat{\mathbf{y}}(k)$

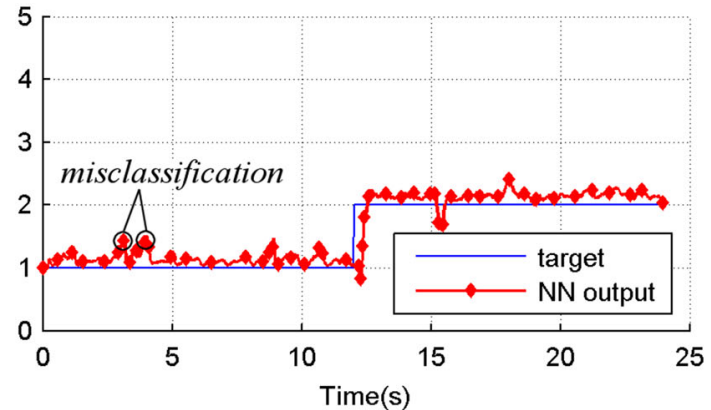

(a) inner race fault

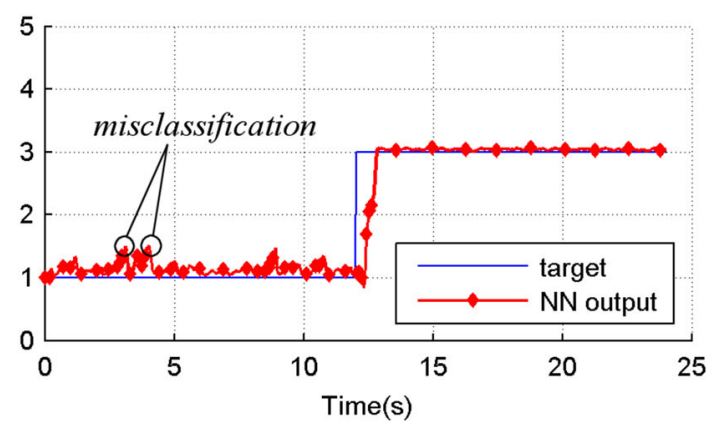

(b) outer race fault

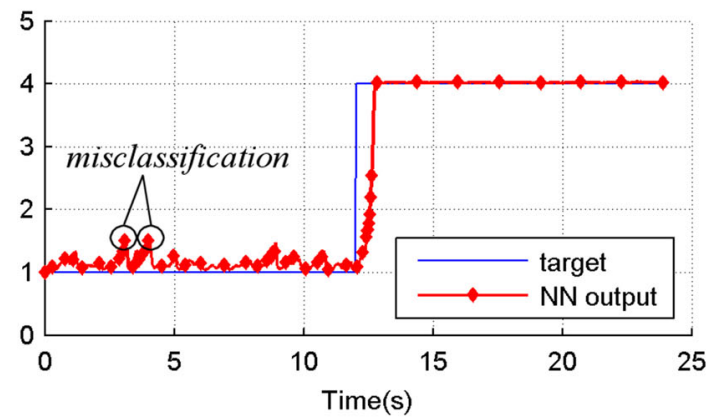

(c) crushed ball fault

Fig. 12 Fault diagnosis test for motor operating at $1200 \mathrm{rpm}$ with variable load

$$
\begin{aligned}
\text { 3. } \boldsymbol{\delta}_{i}^{(2)}(k)= & \mathbf{a}_{i}^{(2)}(k)\left(1-\mathbf{a}_{i}^{(2)}(k)\right) \sum_{n=1}^{4} \Theta_{n i}^{(2)} \boldsymbol{\delta}_{n}^{(3)}(k) ; \\
& i=1, \ldots, n_{h} \\
\Delta_{i j}^{(2)}= & -\frac{1}{m} \sum_{k=1}^{m} \boldsymbol{\delta}_{i}^{(3)}(k) \mathbf{a}_{j}^{(2)}(k) ; \quad i=1, \ldots, 4 ; \\
& j=0, \ldots, n_{h} \\
\Delta_{i j}^{(1)}= & -\frac{1}{m} \sum_{k=1}^{m} \boldsymbol{\delta}_{i}^{(2)}(k) a_{j}^{(1)}(k) ; \quad i=1, \ldots, n_{h} ; \\
& j=0, \ldots, n_{i}
\end{aligned}
$$

where $n_{h}$ is the number of hidden units (not counting the bias unit) and $n_{i}$ the number of input units (not counting the bias unit).

The BP process was applied in two stages. During the first set of iterations, the (delayed) target values $\mathbf{y}_{t}$ were used to construct $\mathbf{x}(k)$ for computation of $\hat{\mathbf{y}}$ in the first step of the BP process, effectively training a network without feedback. 


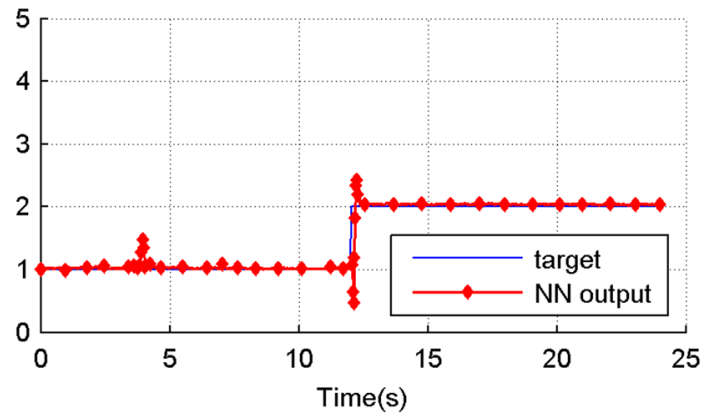

(a) inner race fault

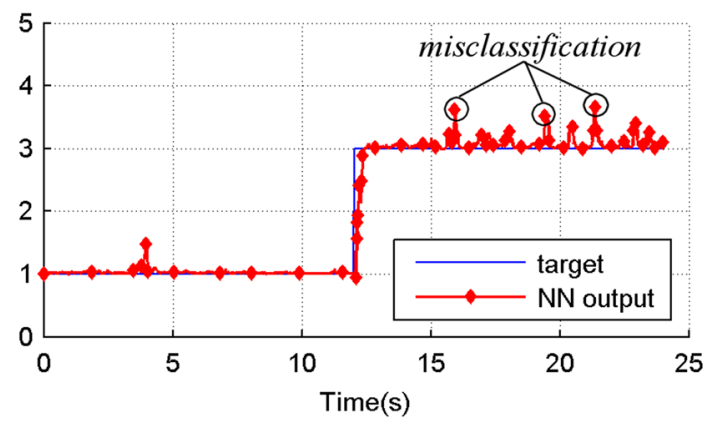

(b) outer race fault

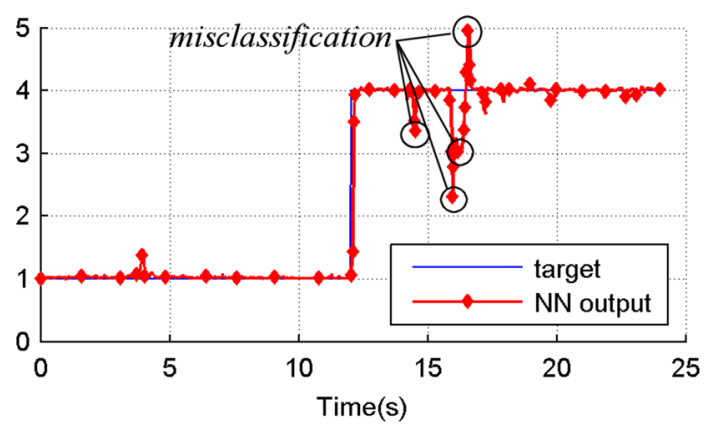

(c) crushed ball fault

Fig. 13 Fault diagnosis test for motor operating at $900 \mathrm{rpm}$ with variable load

During a second stage, (past) predictions of the network $\hat{\mathbf{y}}$ were used to construct $\mathbf{x}(k)$ in accordance with the true feedback architecture of the network. Although the gradients computed with the BP algorithm in this case are approximations to the true gradient, the errors are small as, after the first set of iterations, the network is sufficiently trained to output predictions close to the target values.

\section{Results and Discussion}

From the experimental datasets obtained in the laboratory, $40 \%$ of each was reserved for testing the trained RNN. For each operating condition and each type of fault, a sequence of data from the healthy case was prefixed to the data obtained

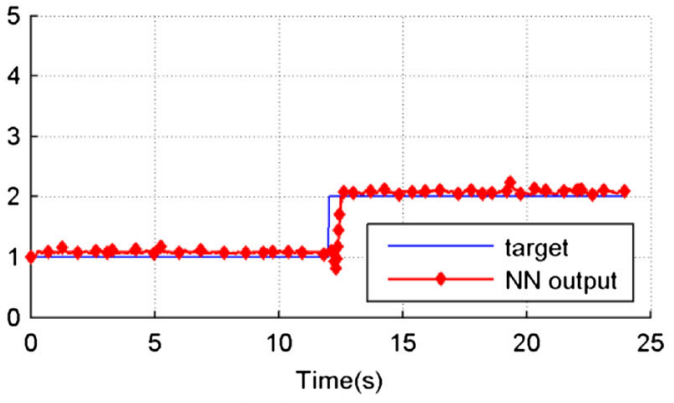

(a) inner race fault

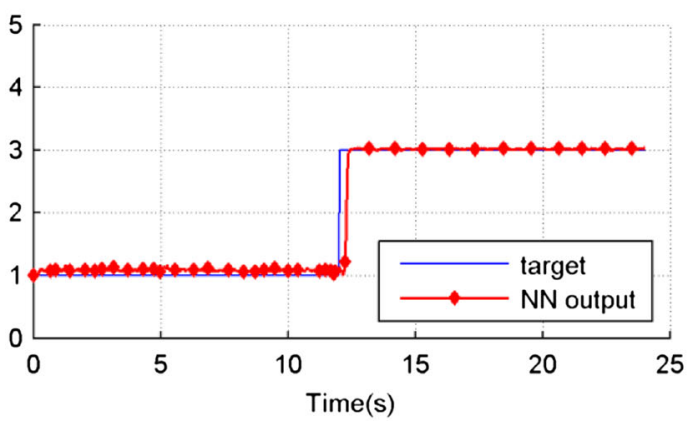

(b) outer race fault

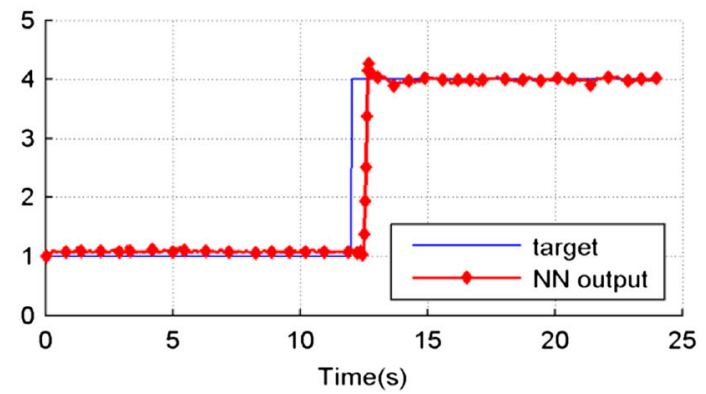

(c) crushed ball fault

Fig. 14 Fault diagnosis test for motor operating at variable speed and maximum loading conditions

from a faulty condition. Wavelet features were obtained for each one, from which three OFNDA features were obtained, as was done with the training data. The OFNDA features were then fed to the input of the trained RNN, to test whether it was capable of detecting and classifying the different faults accurately. Figures 12 and 13 shows DNN Performance under variable load with 900 and rpm speed conditions. In the same manner, Fig. 14 shows DNN output under variable speed conditions.

The output shown is a combination of the four output units of the network calculated as:

$y_{\mathrm{RNN}}(k)=\hat{\mathbf{y}}_{1}(k)+2 \hat{\mathbf{y}}_{2}(k)+3 \hat{\mathbf{y}}_{3}(k)+4 \hat{\mathbf{y}}_{4}(k)$

so that a healthy condition should output a 1 , an outer-race fault a2, an inner-race fault a3, and a crushed ball fault a4. This output is compared with the correct output for each 
Table 6 Test results under variable operating conditions

\begin{tabular}{lllll}
\hline Operating load & Bearing faults & NMC & MMCT (s) & RT (s) \\
\hline 900 rpm, variable load & Inner race & 1 & 0.06 & 0.20 \\
& Outer race & 3 & 0.06 & 0.36 \\
& Ball & 5 & 0.13 & 0.17 \\
$1200 \mathrm{rpm}$, variable load & Inner race & 2 & 0.65 & 0.40 \\
& Outer race & 2 & 0.65 & 0.75 \\
Full load, variable speed & Ball & 2 & 0.65 & 0.75 \\
& Inner race & 0 & 0 & 0.33 \\
& Outer race & 0 & 0 & 0.33 \\
& Ball & 0 & 0 & 0.70 \\
\hline
\end{tabular}

Table 7 Classification accuracy under variable load

\begin{tabular}{llll}
\hline Operating condition & Bearing faults & \multicolumn{2}{l}{ Accuracy $(\%)$} \\
\cline { 3 - 4 } & & OFNDA & PCA \\
\hline $1200 \mathrm{rpm}$ & Inner race & 98.2 & 97.7 \\
& Outer race & 96.7 & 94.3 \\
& Ball & 96.8 & 98.4 \\
$900 \mathrm{rpm}$ & Inner race & 99.3 & 67.6 \\
& Outer race & 98.2 & 77.1 \\
& Ball & 96.8 & 84.7 \\
& Inner race & 97.2 & 90.5 \\
& Outer race & 93.8 & 87.8 \\
& Ball & 95.4 & 86.9 \\
\hline
\end{tabular}

Table 8 Classification accuracy under variable speed

\begin{tabular}{llll}
\hline Operating condition & Bearing faults & \multicolumn{2}{l}{ Accuracy } \\
\cline { 3 - 4 } & & OFNDA & PCA \\
\hline Full load & Inner race & 98.2 & 92.2 \\
& Outer race & 98.8 & 81.3 \\
Half rated load & Ball & 97.4 & 84.7 \\
& Inner race & 94.7 & 82.4 \\
& Outer race & 94.0 & 72.9 \\
No-load & Ball & 93.3 & 79.5 \\
& Inner race & 95.4 & 96.9 \\
& Outer race & 97.8 & 71.3 \\
& Ball & 96.7 & 73.9 \\
\hline
\end{tabular}

dataset. It should be noted that unrounded values are shown in the graphs, and misclassification only occurs when the rounded value does not coincide with the correct value. These are indicated by circles in the graphs.

It should also be noted that the network cannot instantly respond to a faulty condition, due to the delay introduced by the dynamics of the network architecture (feedback loop).

The transition periods are not included in the misclassification count, but the delay is measured as a separate quantity in Table 6, where NMC is the number of misclassifications

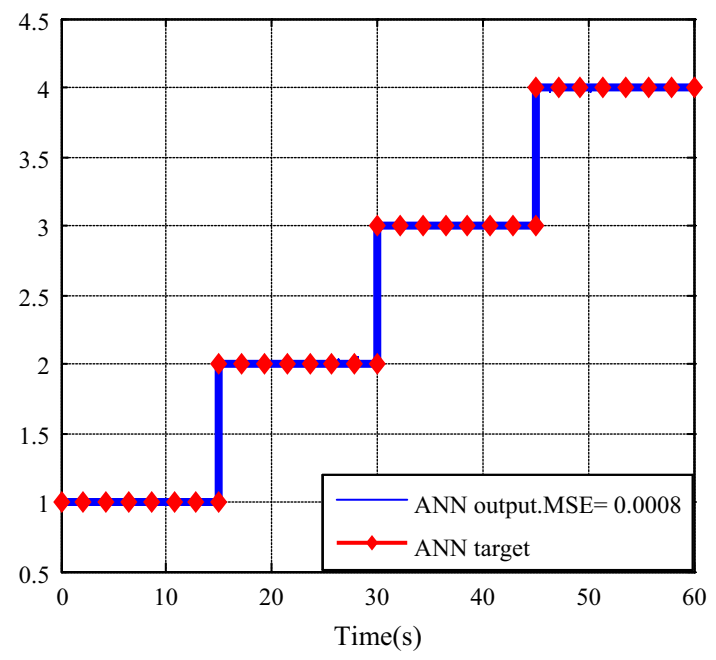

Fig. 15 Overall fault diagnosis test for motor operating at variable load and speed at $1200 \mathrm{rpm}$

and MMCT the maximum misclassification time. RT represents the network's response time to react to the presence of a fault.

Principle component analysis is one of linear feature reduction techniques used to transfer data to a new orthogonal basis whose axes are oriented in the directions of the maximum variance of an input data set. It is commonly used for feature reduction purposes.

Using OFNDA as a feature reduction tool was tested by comparison with PCA. The comparison indicated that feature reduction with the OFNDA technique provided better fault classification accuracy compared to PCA techniques. PCA reduces features by selecting the main three important features. One of the main drawbacks of PCA is that it works to reduce feature redundancy only, without taking into account the relation of features or variables with the specific class labels, and this will affect classification accuracy.

Furthermore, PCA's capability will decrease with nonlinear data (Jia, 2011). Tables 7 and 8 show the percentage diagnostic accuracy of DNN with OFNDA and PCA. After applying PCA as a feature reduction tool, the overall per- 


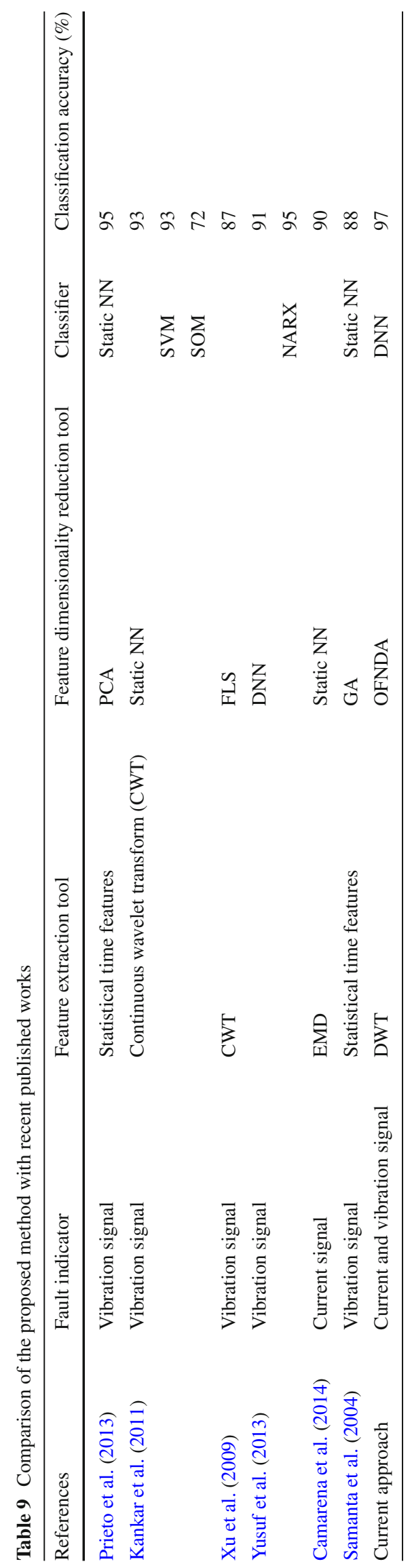

centage accuracy reduced at variable load, with 1200, 900, $600 \mathrm{rpm}$ and variable speed with no-load conditions

All the duration times of the misclassifications are less than $0.7 \mathrm{~s}$. In practice, such misclassification times would not be noticeable. Hence, all the misclassifications can be considered spontaneous and can be ignored. Fig. 15 shows the overall fault diagnosis test for a motor operating at variable load and speed at $1200 \mathrm{rpm}$.

Table 9 shows the comparison of the proposed fault diagnosis technique with recent published works based on soft computing techniques, feature extraction and dimensionality reduction tools. Prieto et al. (2013) used statistics features under different speed and load conditions to train NNs, and the overall classification accuracy for 25 operating tests is $95 \%$ while Kankar et al. (2011) and Samanta et al. (2004) used statistics and wavelet features of vibration signals under stationary operating conditions to train and test different soft computing techniques. Xu et al. (2009), meanwhile, used continuous WT to train fuzzy logic system (FLS) under variable speed conditions.

Yusuf et al. (2013) utilised GA to optimised statistical time features that used to train DNN. In Camarena et al. (2014), EMD of current signals employed to tran NN under nonstationary operating conditions.

In the current approach, the mean accuracy of each test under variable load conditions is $97.23,98.10$ and $95.46 \%$, respectively, and the mean accuracy under variable speed conditions are $98.13,95.36$ and $96.63 \%$, respectively, and the overall classification rate of the current approach is about $97 \%$.

\section{Conclusions}

In this paper, a new intelligent fault diagnosis technique for rolling element bearings in BLDC motors is proposed. A set of fault scenarios were designed and tested under nonstationary operating conditions, including different motor speeds and loads. The stator current and raw vibration signals collected from the experimental setup were used as fault indicators.

Discrete wavelet transform was used as an efficient feature extraction method. However, these features alone are not capable of a good fault classification performance. OFNDA was applied to obtain the best features for fault classification, and the results show that better classification accuracy was obtained. These features were fed to a RNN for fault classification, enabling the fault classifier to incorporate a dynamic component.

The application of these techniques to real data has shown that they constitute an effective fault classifier in practice, capable of detecting and classifying bearing faults under nonstationary operating conditions fairly accurately. 


\section{References}

Abed, W., Sharma, K., \& Sutton, R. (2014). Intelligent fault diagnosis of an unmanned underwater vehicle electric thruster motor. The Global Event for Undersea Defence and Technology Liverpool, UK, 10-12 June.

Abed, W., Sharma, K., \& Sutton, R. (2014). Diagnosis of bearing fault of brushless DC motor based on dynamic neural network and orthogonal fuzzy neighborhood discriminant analysis. In 10 International Conference of the United Kingdom. Automatic Control Council, Loughborough University, UK. doi:10.1109/CONTROL. 2014.6915170.

Al-Timemy, H., Bugmann, G., Escudero, J., \& Outram, N. (2013). Classification of finger movements for the dexterous hand prosthesis control with surface electromyography. IEEE Journal of Biomedical and Health Informatics, 17(3), 608-618.

Alok, S., Kuldip, K., \& Godfrey, C. (2006). Class-dependent PCA, MDC and LDA: A combined classifier for pattern classification, Pattern Recognition, 39(7), 1215-1229.

Antonino, J., Aviyente, S., Strangas, G., \& Riera-Guasp, M. (2013). Scale invariant feature extraction algorithm for the automatic diagnosis of rotor asymmetries in induction motors. IEEE Transactions on Industrial Informatics, 9(1), 100-108.

Bediaga, I., Mendizabal, X., Arnaiz, A., \& Munoa, J. (2013). Ball bearing damage detection using traditional signal processing algorithms. IEEE Instrumentation and Measurement Magazine, 16(2), $20-25$.

Brown, D., Georgoulas, G., Bae, H., \& Vachtsevanos, G. (2009). Particle filter based anomaly detection for aircraft actuator systems. In IEEE Aerospace Conference (pp. 1-13). doi:10.1109/AERO. 2009.4839659.

Camarena, D., Valtierra, M., Garcia, A., Osornio, A., \& Romero, J. (2014). Empirical mode decomposition and neural networks on FPGA for fault diagnosis in induction motors. The Scientific World Journal. doi:10.1155/2014/908140.

Delgado, M., Cusido, J., \& Romeral, L. (2011). Bearings fault detection using inference tools. In Tech. doi:10.5772/22696.

Goharrizi, Y., \& Sepehri, N. (2010). A wavelet-based approach to internal seal damage diagnosis in hydraulic actuators. IEEE Transactions on Industrial Electronics, 57(5), 1755-1763.

Howard, D., Mark, B., \& Martin, H. (2006). Neural network toolbox for use with MATLAB. The Mathowrks User's Guide, Version 5.

Hyun, C., Knowles, J., Fadali, S., \& Kwon, L. (2010). Fault detection and isolation of induction motors using recurrent neural networks and dynamic Bayesian modeling. IEEE Transactions on Control Systems Technology, 18(2), 430-437.

Immovilli, F., Bellini, A., Rubini, R., \& Tassoni, C. (2010). Diagnosis of bearing faults in induction machines by vibration or current signals: A critical comparison. IEEE Transactions on Industry Applications. doi:10.1109/08IAS.2008.26.

Jia, G., Yuan, S., \& Tang, C. (2011). Fault diagnosis of roller bearing based on PCA and multi-class support vector machine. Computer and Computing Technologies in Agriculture. Berlin Heidelberg: Springer. doi:10.1007/978-3-642-18369-0_22.

Jin, X., Zhao, M., Chow, T., \& Pecht, M. (2013). Motor bearing fault diagnosis using trace ratio linear discriminant analysis. IEEE Transactions on Industrial Electronics, 61(5), 1-11.

Jun, H., Jianzhong, Z., Ming, C., \& Zheng, W. (2013). Fault diagnosis of mechanical unbalance for permanent magnet synchronous motor drive system under nonstationary condition. In: IEEE energy conversion and exposition conference, USA. doi:10.1109/ECCE. 2013.6647169.

Kankar, K., Sharma, C., \& Harsha, P. (2011). Fault diagnosis of ball bearings using continuous wavelet transform. Applied Soft Computing, 11(2), 2300-2312.
Khushaba, N., Al-Ani, A., \& Al-Jumaily, A. (2010). Orthogonal fuzzy neighborhood discriminant analysis for multifunction myoelectric hand control. IEEE Transactions on Biomedical Engineering, 57(6), 1410-1419.

Mahammed, A., \& Hiyama, T. (2011). Fault classification based artificial intelligent methods of induction motor. International Journal of Innovative Computing, Information and Control, 7(9), 54775493.

Michie, D., Spiegelhalter, D., \& Taylor, C. (2009). Machine learning, neural and statistical classification (1st ed.). Chichester: Ellis Harwood.

Patil, M., Mathew, J., Rajendrakumar, P., \& Desai, S. (2010). A theoretical model to predict the effect of localized defect on vibrations associated with ball bearing. International Journal of Mechanical Sciences, 52(9), 1193-1201.

Phinyomark, A., Nuidod, A., Phukpattaranont, P., \& Limsakul, C. (2012). Feature extraction and reduction of wavelet transform coefficients for EMG pattern classification. Electrical and Electronics Engineering, 122(6), http://www.eejournal.ktu.lt/index.phpelt/ article/view/1816.

Prieto, D., Cirrincione, G., Espinosa, G., Ortega, A., \& Henao, H. (2013). Bearing fault detection by a novel condition-monitoring scheme based on statistical-time features and neural networks. IEEE Transactions on Industrial Electronics, 60(8), 33983407.

Rao, B., Pai, S., \& Nagabhushana, T. (2012). Failure diagnosis and prognosis of rolling-element bearings using artificial neural networks: A critical overview. IOP Publishing, Journal of Physics: Conference Series, 364(1), 1-28.

Sadough Vanini, Z. N., Khorasani, K., \& Meskin, N. (2014). Fault detection and isolation of a dual spool gas turbine engine using dynamic neural networks and multiple model approach. Information Science, 259, 234-251.

Safavian, L., Kinsner, W., \& Turanli, H. (2005). Aquantitative comparison of different mother wavelets for characterizing transients in power systems. In IEEE conference on Electrical and Computer Engineering, (pp. 1461-1464) doi:10.1109/CCECE.2005. 1557253.

Samanta, B., Al-Balushi, R., \& Al-Araimi, A. (2004). Bearing fault detection using artificial neural networks and genetic algorithm. Journal on Applied Signal Processing, 2004(3), 366-377.

Seshadrinath, J., Singh, B., \& Panigrahi, K. (2014). Investigation of vibration signatures for multiple fault diagnosis in variable frequency drives using complex wavelets. IEEE Transactions on Power Electronics, 29(2), 936-945.

Seshadrinath, J., Singh, B., \& Panigrahi, K. B. (2012). Incipient turn fault detection and condition monitoring of induction machine using analytical wavelet transform. In IEEE Industry Applications Society Annual Meeting, USA. doi:10.1109/IAS.2012.6374026.

Subhasis, N., Hamid, T., \& Xiaodong, L. (2005). Condition monitoring and fault diagnosis of electrical motors a review. IEEE Transactions on Energy Conversion, 20(4), 719-729.

Sugumaran, V., \& Ramachandran, I. (2011). Effect of number of features on classification of roller bearing faults using SVM and PSVM. Expert Systems with Applications, 38(4), 4088-4096.

Tavner, J. (2008). Review of condition monitoring of rotating electrical machines. Electric Power Applications, IET, 2(4), 215-247.

Trajin, B., Regnier, J., \& Faucher, J. (2009). Comparison between stator current and estimated mechanical speed for the detection of bearing wear in asynchronous drives. IEEE Transactions on Industrial Electronics, 56(11), 4700-4709.

Vachtsevanos, G., \& Wang, P. (2001). Fault prognosis using dynamic wavelet neural networks. EEE Systems Readiness Technology Conference, USA. doi:10.1109/AUTEST.2001.949467. 
Wang, T., Liang, M., Li, J., \& Cheng, W. (2014). Rolling element bearing fault diagnosis via fault characteristic order analysis. Mechanical Systems and Signal Processing, 45(1), 139-153.

Wu, Y., Lai, H., \& Lin, S. (2013). Feature extraction for bearing detection identification under variable rotation speed. In 20th International Congress on sound and vibration, Thailand. http://www. icsv20.org/index.php?va=viewpage \&vaid=175\&vasort=title.

Xu, Z., Xuan, J., Shi, T., Wu, B., \& Hu, Y. (2009). Application of a modified fuzzy ARTMAP with feature-weight learning for the fault diagnosis of bearing. Expert Systems with Applications, 36(6), 9961-9968.

Xuhong, W., \& Yigang, H. (2005). Diagonal recurrent neural network based on-line stator winding turn fault detection for induction motors. Electrical Machines and Systems, Proceedings of the Eighth International. doi:10.1109/ICEMS.2005.202972.

Yang, H., Mathew, J., \& Ma, L. (2002). Intelligent diagnosis of rotating machinery faults-a review. In 3rd Asia-Pacific conference on systems integrity and maintenance, Australia. http://eprints.qut.edu. au/17942/1/17942.pdf.
Yilmaz, S., \& Ayaz, E. (2009). Adaptive neuro-fuzzy inference system for bearing fault detection in induction motors using temperature, current, vibration data. EUROCON conference, Russia. doi:10.1109/EURCON.2009.5167779.

Yusuf, A., Brown, J., Mackinnon, A., \& Papanicolaou, R. (2013). Application of dynamic neural networks with exogenous input to industrial conditional monitoring. International joint conference on neural networks, USA. 1-8. doi:10.1109/IJCNN.2013. 6706762.

Zhang, Y., Zuo, H., \& Bai, F. (2013). Classification of fault location and performance degradation of a roller bearing. Measurement, 46(3), $1178-1189$.

Zhenyu, Y., Uffe, M., Gerfulf, P., Morten, R., \& hakon, B. (2009). A study of rolling-element bearing fault diagnosis using motor's vibration and current signatures, preprints of the 7th IFAC symposium on fault detection, supervision and safety of technical processes, Spain. doi:10.3182/20090630-4-ES-2003.00059. 